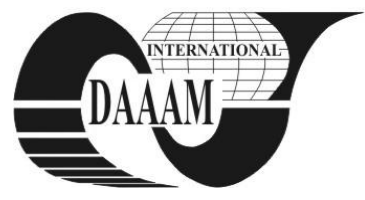

Annals of DAAAM for 2011 \& Proceedings of the 22nd International DAAAM Symposium, Volume 22, No. 1, ISSN 1726-9679 ISBN 978-3-901509-83-4, Editor B. Katalinic, Published by DAAAM International, Vienna, Austria, EU, 2011 Make Harmony between Technology and Nature, and Your Mind will Fly Free as a Bird Annals \& Proceedings of DAAAM International 2011

\title{
ESTIMATING SOIL HEAT FLUX AT SURFACE SOIL LAYER
}

\author{
HOFREITER, M[ilan]
}

\begin{abstract}
This article describes a method for establishing the soil heat flux at the surface soil layer. The method was used to determine the evapotranspiration in ecosystems. This approach is applicable for both daytime and night-time conditions. The soil heat flux is estimated through the derived mathematical model, which requires the measuring of the two soil temperatures near the soil surface. The method was verified during the determination of the evapotranspiration in the southern part of the Czech Republic.
\end{abstract}

Key words: heat flux, evapotranspiration, soil, mathematical model

\section{INTRODUCTION}

Evapotranspiration transforms tens of percent of incoming solar energy, equalizes differences in temperatures, determines primary productions and holds nutrients in the soil. Direct measurement of evapotranspiration is difficult and requires very costly equipment. Therefore, methods are sought to make it possible to determine evapotranspiration from commonly measurable hydrometeorological parameters. A series of mathematical models reflecting the links between the energetic and hydraulic conditions was developed for this purpose. Evaporation of water requires relatively large amounts of energy. The energy entering the evaporation surface must equal the energy leaving the surface during the same time period (Allen et al., 1998; Novak, 1995; Hofreiter, 2008). Therefore

$$
R n=\lambda \cdot E T+H+G+A_{f}+A_{c}
$$

where $R n$ is the intensity of the net radiation $\left[\mathrm{W} \cdot \mathrm{m}^{-2}\right]$ (i.e. the difference between the incoming and outgoing radiation of both short and long wavelengths); $\lambda \cdot E T$ is the latent heat flux consumed during evapotranspiration $\left[\mathrm{W} \cdot \mathrm{m}^{-2}\right] ; H$ is the intensity of the sensible heat flux $\left[\mathrm{W} \cdot \mathrm{m}^{-2}\right] ; G$ is the intensity of the soil heat flux $\left[\mathrm{W} \cdot \mathrm{m}^{-2}\right] ; \lambda$ is the latent heat of vaporization $\left[\mathrm{J} \cdot \mathrm{kg}^{-1}\right] ; E T$ is the intensity of evapotranspiration $\left[\mathrm{kg} \cdot \mathrm{m}^{-2} \cdot \mathrm{s}^{-1}\right] ; A_{f}$ is the intensity of the heat flux consumed during photosynthesis $\left[\mathrm{W} \cdot \mathrm{m}^{-2}\right]$ and $A_{c}$ is the intensity of the biomass thermal capacitance change $\left[\mathrm{W} \cdot \mathrm{m}^{-2}\right]$. Accordingly (Novak, 1995)

$$
A_{f} \square 2 \% R n
$$

and

$$
A_{c}<A_{f},
$$

therefore $A_{f}$ and $A_{c}$ are much less than the other factors in (1) and thus are negligible. This is in accordance with (Allen et al., 1998)

$$
R n \square \lambda \cdot E T+H+G,
$$

where only the vertical fluxes are considered and the horizontal fluxes are ignored. The evapotranspiration (ET) can be computed using formula (4) if $R n, H, G$ are known. These variables change during the day and therefore it is necessary to find out their values in time. Some of these energy fluxes can be measured directly and others are established indirectly on the basis of the measurements of related physical quantities and subsequent calculations. A series of mathematical models was developed for this purpose (Allen et al., 1998). Because of the system complexity and difficulties associated with the continuous measurement of weather quantities, the links are most often described by non-linear static models involving a dominant impact of a global nature. This paper focuses on the estimation of $G$ for this purpose.

The soil heat flux $G$ is typically smaller than $H$ or $\lambda \cdot E T$ and for daylight, $G$ is commonly approximated according to (Allen et al., 1998)

$$
G=0.4 \cdot e^{-0.5 \cdot L A I} \cdot R n=\delta \cdot R n,
$$

where $L A I$ is the leaf area index and

$$
\delta \square 0.4 \cdot e^{-0.5 \cdot L A I} .
$$

In some papers authors consider $G$ as a residual term of energy balance or assume it to be negligible on daily timescales (Santanello \& Friedl, 2003). Many empirical studies (Allen et al., 1998; Liang et al., 1999; Santanello \& Friedl, 2003) have shown that $G$ is not constant and that $G / R n$ can range from 0.05 to 0.50 .Furthermore, this all depends, except for the $L A I$, on the time of day, the soil moisture and the thermal properties as well. Sensitivity analyses show that if these changes are ignored then significant errors in modeled flux terms can result. Some authors estimate $G$ in an analytical way, based on Fourier's law and the assumption of a monotonous temperature profile in the ground (Liang et al., 1999) or an ideal harmonic temperature behaviour in a 24-hour cycle and homogenous characteristics (Monteith \& Unsworth, 1990). Direct measurement of the heat flux $(G)$ at the vegetation-soil boundary is extremely difficult because it depends on many factors, e.g. the thermal properties of the soil, the locality of the heat flux sensor, vegetation, vegetation period, climatic conditions. The distorted estimate of heat flux $(G)$ is then reflected in the distorted estimate of the evapotranspiration $(E T)$.

\section{ESTIMATION OF THE SOIL HEAT FLUX}

At a depth $z$ below the soil surface, the downward flux of heat in the soil is given by Fourier's law

$$
G(z, \tau)=-\lambda_{s} \frac{\partial \vartheta(z, \tau)}{\partial z}
$$

where $\lambda_{s}$ is the soil thermal conductivity, $\vartheta(z, \tau)$ is the soil temperature at depth $z$ at time $\tau$. In the surface soil layer at a shallow depth $z_{1}$, the difference between the heat flux $G=G(0, \tau)$ entering the layer at time $\tau$ and at level $z=0$ and leaving at $z=z_{1}$ is $G=G(0, \tau)$. The law of energy conservation holds for the surface soil layer after discretization

$G \square \tau-\lambda_{s} \frac{\left(\vartheta_{1}(\tau)-\vartheta_{2}(\tau)\right)}{z_{1}} \square \tau=\rho_{s} z_{1} c_{s}\left(\vartheta_{1}(\tau+\square \tau)-\vartheta_{1}(\tau)\right)$

where $\rho_{s}$ is the soil density, $\vartheta_{1}(\tau)=\vartheta\left(z_{1} / 2, \tau\right), \vartheta_{2}(\tau)=\vartheta\left(z_{1}+z_{1} / 2, \tau\right)$, $\Delta \tau$ is the time interval and $c_{s}$ is the soil specific heat. From (8) it follows

$$
G=\rho_{s} \cdot z_{1} \cdot c_{s} \cdot \frac{\left(\vartheta_{1}(\tau+\square \tau)-\vartheta_{1}(\tau)\right)}{\square \tau}+\lambda_{s} \frac{\left(\vartheta_{1}(\tau)-\vartheta_{2}(\tau)\right)}{z_{1}},
$$


where the uniform soil thermal properties in the surface soil layer are assumed.

\section{SOIL THERMAL PROPERTIES}

The volumetric heat capacity of soil $C_{s}$ can be established

$$
C_{s}=\rho_{s} \cdot c_{s}=\rho_{m} c_{m} x_{m}+\rho_{o} c_{o} x_{o}+\rho_{w} c_{w} x_{w}+\rho_{a} c_{a} x_{a},
$$

where the symbol $x$ is the volume fraction of a component in soil, $c$ is the specific heat, $\rho$ is the density and the subscripts $m$, $o, w$ and $a$ represent the mineral, organic, water and air components. From (Brutsauert, 1991) $\rho_{m}=2650 \mathrm{~kg} \cdot \mathrm{m}^{-3}, \rho_{o}=1300$ $\mathrm{kg} \cdot \mathrm{m}^{-3,}, \rho_{a}=1.2 \mathrm{~kg} \cdot \mathrm{m}^{-3}, \rho_{w}=2650 \mathrm{~kg} \cdot \mathrm{m}^{-3}, \quad c_{m}=733 \mathrm{~J} \cdot \mathrm{kg}^{-1} \cdot \mathrm{K}^{-1}$, $c_{o}=1296 \mathrm{~J} \cdot \mathrm{kg}^{-1} \cdot \mathrm{K}^{-1}, c_{w}=4182 \mathrm{~J} \cdot \mathrm{kg}^{-1} \cdot \mathrm{K}^{-1}, c_{a}=1010 \mathrm{~J} \cdot \mathrm{kg}^{-1} \cdot \mathrm{K}^{-1}$. It holds

$$
x_{m}+x_{o}+x_{w}+x_{a}=1,
$$

where $x_{m}, x_{o}, x_{w}$ and $x_{a}$ follow from soil analysis.

The soil thermal conductivity $\lambda_{s}$ can be a difficult parameter to estimate, since it depends not only on the volumetric water content, but also on mineral composition, porosity and dry density (Peters-Lidard et al., 1998). The thermal conductivity $\lambda_{s}$ was calculated according to (Liang et al, 1999; Peters-Lidard et al., 1998) as a combination of dry $\lambda_{d r y}$ and saturated $\lambda_{\text {sat }}$ thermal conductivities, weighted by the Kersten number $K_{e}$.

$$
\lambda_{s}=K_{e}\left(\lambda_{s a t}-\lambda_{d r y}\right)+\lambda_{d r y},
$$

where for unfrozen soils

$$
\begin{gathered}
K_{e}=\left\{\begin{array}{c}
0.7 \log S_{w}+1.0 \text { for } S_{w}>0.05 \text { and coarse soil } \\
\log S_{w}+1.0 \text { for } S_{w}>0.1 \text { and fine soil }
\end{array},\right. \\
\lambda_{d r y}=\frac{0.135 \cdot \rho_{d r y}+64.7}{2700-0.947 \cdot \rho_{d r y}}, \\
\lambda_{\text {sat }}=\lambda_{\text {sol }}^{1-x_{p o r}} \cdot \lambda_{w}^{x_{p o r}}, \\
x_{p o r}=x_{a}+x_{w}, \\
S_{w}=\frac{x_{w}}{x_{p o r}}, \\
\rho_{d r y}=\rho_{m} \cdot x_{m}+\rho_{o} \cdot x_{o}+\rho_{a} \cdot x_{p o r},
\end{gathered}
$$

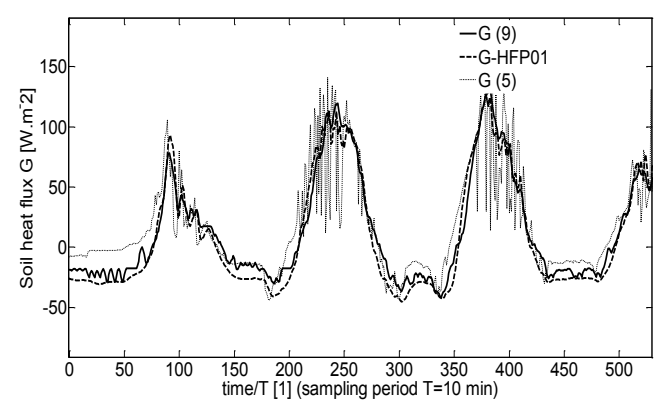

Fig. 1 Soil heat flux $G$ calculated according formulas (5), (9) and measure using HFP01

$S_{w}$ is the water saturation, $x_{p o r}$ is the porosity, $\lambda_{\text {sol }}$ is the thermal conductivity of solids, $\lambda_{w}$ is the thermal conductivity of water and $\rho_{d r y}$ is the dry density.

\section{APPLICATION}

The method was implemented in the Matlab program environment and tested on the observed data measured at the meteorological station called "Vrt Domanin" near the town of Trebon in southern Bohemia. The following variables were measured for the determination of the soil heat flux $(G)$ : the volumetric soil moisture $x_{w}$ and the soil temperatures $\vartheta_{1}$ and $\vartheta_{2}$ at the depth $0.01 \mathrm{~m}$ and $0.02 \mathrm{~m}$. The soil thermal properties were obtained by the soil analysis. The course of the soil heat flux $(G)$ calculated according formula (9) was compared with the data measured using Huxeflux Heat Flux Plate (HFP01) and with data calculated using formula (5). The intensity of the net radiation $R n$ was measured by the Net Radiometer (CNR1) manufactured by Kipp \& Zonen. The data was recorded at 10 minute intervals. The results in Figure 1 show the consistency between the values of the soil heat flux measured by the HFP01 and those calculated using formula (9). The fluctuation of the soil heat flux calculated using formula (5) is caused by clouds.

\section{CONCLUSION}

The method requires the measurement of only two soil temperatures near the surface and the measurement of the soil's volumetric water content. The other parameters can be found using one-off soil analysis. The method enables one to estimate the soil heat flux continuously during day and night conditions. This approach does not assume a monotonous temperature profile in the soil as it is usually done. The influence of clouds on the estimate is partly filtered out by the soil's capacity. This method requires accurate temperature measuring. Additionally this approach is more accurate than the method based on formula (5) and it does not require the knowledge of the leaf area index (LAI) or the use of special probes. The more accurate estimate of the soil heat flux with regard to (4), results in a more accurate estimate of the intensity of evapotranspiration (ET).

Further research will concentrate on the more accurate modelling of energy and evapotranspiration flows with respect to the dynamics of events taking place in an ecosystem at the vegetation-atmosphere boundary. Various types of vegetation will be included in order to improve a continuous estimate and the prediction of energy and evapotranspiration flows during the day in selected locations.

\section{ACKNOWLEDGEMENTS}

The work is supported by the Ministry of Education of the Czech Republic under Project TOKENELEK, No. 2 B06023.

\section{REFERENCES}

Allen, R. G.; Pereira, L. S.; Raes, D. \& Smith, M. (1998). Crop Evapotranspiration - Guidelines for Computing Crop Water Requirements, FAO Irrigation and drainage paper 56, Food and Agriculture Organization of United Nations, ISBN 92-5104219-5, Rome

Brutsauert, W. (1991). Evaporation into the Atmosphere, Kluwer Academic Publishers, ISBN 90-277-1247-6, Dordrecht

Hofreiter, M. (2008) Sensitivities of Crop Evapotranspiration Models to Input Data, Proceedings of 12th International Research/Expert Conference TMT2008, Proceedings. Zenica: Faculty of Mechanical Engineering in Zenica, Ekinovic, S. (Ed.), pp. 1029-1032. ISBN 978-9958-617-41-6

Liang, X.; Wood, E. F. \& Lettenmaier, D. P. (1999) Modeling Ground Heat Flux in Land Surface Parameterization Schemes, Journal of Geophysical Research, Vol. 104, No. D8, April 1999, pages 9851-9600, ISSN 0148-0227

Monteith, J. \& Unsworth, M. (2008). Principles of Environmental Physics, Elsevier Inc., ISBN 978-0-12505103-3, San Diego

Novak, V. (1995) Evaporation of Water in Nature and Methods of its Determining, (in Slovak), VEDA SAV, ISBN 80-2240409-8, Bratislava

Peters-Lidard, C. D.; Blackburn, E.; Liang, X. \& Wood, E. F. (1998) The Effect of Soil Thermal Conductivity Parameterization on Surface Energy Fluxes and Temperatures, Journal of the Atmospheric Sciences, Vol. 55, No. 7, April 1998, pages 1209-1224, ISSN 0022-4928

Santanello, J. A. \& Friedl M. A. (2003) Diurnal Covariation in Soil Heat Flux and Net Radiation, Journal of Applied Meteorology, Vol. 42, No. 6, June 2003, pages 851-862, ISSN 0894-8763 